\title{
Feedback Stabilization of Fed-Batch Bioreactors: Non-Monotonic Growth Kinetics
}

\author{
I Ise Y. Smets, ${ }^{\dagger}$ Georges P. Bastin, ${ }^{\ddagger}$ and J an F. Van Impe*,†
}

BioTeC-Bioprocess Technology and Control, Department of Chemical Engineering, Katholieke Universiteit Leuven, Kasteel park Arenberg 22 B-3001 Leuven, Belgium, and CESAME, Université Catholique de Louvain, B-1348 Louvain-la-Neuve, Belgium

\begin{abstract}
This paper deals with the design of a feedback controller for fed-batch microbial conversion processes that forces the substrate concentration $C_{S}$ to a desired setpoint $\mathrm{C}_{\mathrm{S}}^{*}$, starting from an arbitrary (initial) substrate concentration when non-monotonic growth kinetics apply. This problem is representative for a lot of industrial fermentation processes, with the baker's yeast fermentation as a well-known example. It is assumed that the specific growth rate $\mu$ is function of the substrate concentration only. A first approach exploits the availability of on-line measurements of both the substrate and biomass concentration. A second approach is merely based on on-line measurements of the biomass concentration, which provide an estimate for the specific growth rate. After a reformulation of the substrate concentration setpoint into a specific growth rate setpoint, it is demonstrated that the fed-batch process can still be stabilized around any desired operating point along the non-monotonic kinetics.
\end{abstract}

\section{Introduction}

Given the recent reorientation of some key players in the bulk chemical industry toward the field of lifesciences in which fed-batch processes are predominant (e.g., production of baker's yeast, food additives, and recombinant proteins), optimization and control of fed-batch bioreactors has become more challenging than ever.

To avoid undesired side reactions (due to inhibition or repression mechanisms) the feed rate of fed-batch production processes is most often controlled such that a prespecified substrate concentration, metabolite concentration, or specific growth rate setpoint is maintained. A variety of open loop as well as closed loop control strategies can be found in the literature.

Although feedforward control, i.e., open loop strategies, are not robust against process disturbances (e.g., feeding pump failures), varying initial conditions and model inaccuracies, they are still frequently encountered in the literature (see, for example, refs 1-4). They all propose an exponential feed rate, which keeps the specific growth rate close to a prespecified setpoint, selected as to avoid byproduct formation (such as ethanol and acetate).

On the other hand, the implementation of feedback control laws, although more robust, is hampered by the lack of suitable, generic, and cheap sensors. Léonard et al. developed a PI controller to keep the phenol concentration in a phenol biodegradation process by Ralstonia eutropha at a constant setpoint of $0.1 \mathrm{~g} / \mathrm{L}$, corresponding with a specific growth rate cl ose to the maximum specific growth rate (5). As a result of the production of a metabolic intermediate of the phenol catabolic pathway, a yellow color appears, on the basis of which the on-line concentration of phenol can be estimated.

* To whom correspondence should be addressed. Tel: +32-1632.14.66. Fax: +32-16-32.19.60. E-mail: jan.vanimpe@ agr.kuleuven.ac.be

† BioTeC.

$\ddagger$ CESAME.
To control fed-batch fermentations of E. coli, Kleman et al. try to match the glucose feed rate with the glucose demand, calculated on the basis of on-line glucose measurements (6). The controller is essentially a feedback proportional control of the feed rate around a moving feed rate setpoint, which is predicted from the linear regression of the last five calculated glucose demand data points.

To avoid acetate formation, which inhibits cell growth and production of recombinant protein production, Turner et al. measured the gal actose and acetate concentration with an on-line HPLC device (7). Once the corresponding threshold values are exceeded, a preset reduction of the feed rate is performed. Likewise, Shimizu et al. demonstrate that a high $\mathrm{E}$. coli cell density could be obtained by using feedback feed rate control interfaced with an isotachophoric analyzer (a kind of electrophoresis, in which ion species of the same charge are given the same velocity in an electric field) and a gas chromatograph providing on-line acetate concentration measurements, to keep acetate at low, noninhibiting levels (8).

Within the framework of a study devoted to modeling and fed-batch control, the influence of acetic acid production on S. cerevisiae growth kinetics is investigated by Pons et al. (9). Although respiratory quotient (RQ) measurements have widely been used as an indicator for ethanol formation in growth of baker's yeast, owing to the easy and reliable operation of the oxygen and carbon dioxide analyzers (e.g., refs 10-14), Pons and co-workers illustrate that RQ control is not suited for all strains. Indeed, overfeeding glucose induces ethanol formation but the corresponding $\mathrm{CO}_{2}$ overproduction is masked in the RQ formula by the $\mathrm{O}_{2}$ overconsumption due to acetate production.

Because ethanol production is the main factor observed in the switching from growth with high yield to growth with high productivity in yeast fermentations, its regulation has become extremely important. Several authors 


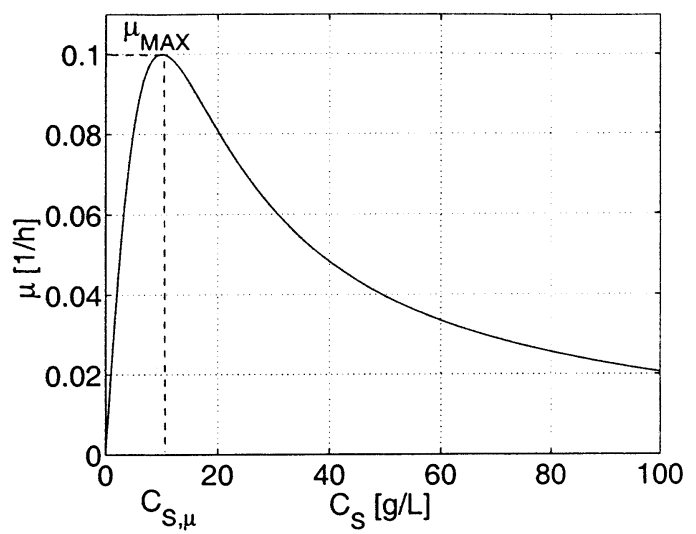

Figure 1. Haldane kinetics.

propose control strategies relying on on-line measure ments of ethanol. Dairaku et al. developed a feedback control system for the glucose feed rate to maximize baker's yeast production in a fed-batch culture (15). Relying on a porous Teflon tubing method, they keep the ethanol concentration constant, and as such, the ethanol production rate is kept at zero. Nanba et al. impose the classical exponential feed rate unless the average value of the last six ethanol measurements reveals an increasing trend (16). Axelsson et al. propose a traditional PID controller around a (prespecified) exponential dosage scheme based on a reducing gas analyzer (17). To avoid the drift of ethanol concentration to higher values during the latter part of the cultivation (due to the mismatch of the substrate demand and the precalculated dosage scheme), Hagander et al. introduce an observer for the exponentially growing feed rate demand (18). The a priori knowledge of the feed rate profile is further relaxed by also incorporating adaptation of the growth rate parameter. Valentinotti et al. present a linear controller to operate a fed-batch baker's yeast fermentation at nearly maximum specific growth rate by maintaining the ethanol concentration at a low but still measurable setpoint (19). Chen et al. developed an adaptive nonlinear controller that regulates the ethanol concentration, to enable a good tradeoff between yield and productivity (20).

All of these control strategies critically depend on online measurements of particular substrates and/or products involved in the reaction pathways followed and are therefore very process-specific. Furthermore, if nonmonotonic kinetics are assumed, the desired operating point can be an open loop unstable setpoint. Hence, stabilization becomes crucial, since a small fluctuation of the feed rate can cause either limitation or accumulation, inducing diminished productivity or collapse of the system (5). Furthermore it is known that classical PID controllers can fail to stabilize the process if the tuning parameters are not carefully selected (21).

The aim of this study is to design a generic and robust stabilizing feedback control algorithm that forces the substrate concentration to reach a prespecified value in a fed-batch microbial growth process when non-monotonic kinetics apply. As a working example to present the main concepts and results, the following Haldanetype growth kinetics is considered (1) (Figure 1):

$$
\mu=\mu_{\mathrm{m}} \frac{\mathrm{C}_{\mathrm{S}}}{\mathrm{C}_{\mathrm{S}}+\mathrm{K}_{\mathrm{P}}+\frac{\mathrm{C}_{\mathrm{S}}^{2}}{\mathrm{~K}_{\mathrm{l}}}}
$$

where $\mu_{\mathrm{m}}[1 / \mathrm{h}], \mathrm{K}_{\mathrm{I}}[\mathrm{g} / \mathrm{L}]$, and $\mathrm{K}_{\mathrm{P}}[\mathrm{g} / \mathrm{L}]$ are specific constants. This type of kinetics is representative for, e.g., baker's yeast fermentation.

Depending on the objective of the process, the value of the substrate concentration has to be chosen small or large. In the example of baker's yeast fermentative growth, a small left flank setpoint favors biomass production while a large right flank setpoint favors ethanol production.

The organization of this paper is as follows. First, the design of a control algorithm under the assumption of on-line measurements for the substrate concentration $\mathrm{C}_{\mathrm{s}}$ and the biomass concentration $C_{x}$ is discussed in Section 2. Afterward, in Section 3, this control law is adapted toward a controller based only on on-line measurements of the biomass concentration $C_{x}$. Section 4 summarizes the main conclusions.

\section{On-line measurements of $C_{s}$ and $C_{x}$}

2.1. Optimal Control. In general, following mass balance equations apply to a fed-batch bioreactor

$$
\begin{gathered}
\frac{\mathrm{d} \mathrm{C}_{\mathrm{S}}}{\mathrm{dt}}=-\sigma \mathrm{C}_{\mathrm{X}}+\frac{\mathrm{u}}{\mathrm{V}}\left(\mathrm{C}_{\mathrm{S}, \text { in }}-\mathrm{C}_{\mathrm{S}}\right) \\
\frac{\mathrm{d} \mathrm{C}_{\mathrm{X}}}{\mathrm{dt}}=\mu \mathrm{C}_{\mathrm{X}}-\frac{\mathrm{u}}{\mathrm{V}} \mathrm{C}_{\mathrm{X}} \\
\frac{\mathrm{dV}}{\mathrm{dt}}=\mathrm{u} \\
\sigma=\frac{\mu}{\mathrm{Y}_{\mathrm{X} / \mathrm{S}}}+\mathrm{m}
\end{gathered}
$$

with $C_{x}[g / L]$ the biomass concentration in the reactor, $\mathrm{C}_{\mathrm{s}}[\mathrm{g} / \mathrm{L}]$ the (limiting) substrate concentration in the reactor, $C_{S \text {,in }}[\mathrm{g} / \mathrm{L}$ ] the (fixed) substrate concentration in the influent, $\mathrm{V}[\mathrm{L}]$ the vol ume of the liquid phase in the reactor, $u[1 / \mathrm{h}]$ the flow rate, $\sigma[1 / \mathrm{h}]$ the specific substrate consumption rate, $\mu[1 / \mathrm{h}]$ the specific growth rate ( eq $1), m[1 / h]$ the specific maintenance coefficient, and $Y_{X / S}$ [-] the yield coefficient of biomass on substrate. Based on the assumption that the (kinetics in the) model is perfectly known, the minimum principle of Pontryagin (22) provides the optimal feed rate $u^{*}$, which maximizes a prespecified control objective. If the control objective is to maximize the final amount of biomass the optimal control law is the following (see, e.g., ref 23):

$$
\mathrm{u}^{*}=\frac{\sigma \mathrm{C}_{\mathrm{X}}}{\mathrm{C}_{\mathrm{S}, \mathrm{in}}-\mathrm{C}_{\mathrm{S}}^{*}} \mathrm{~V}
$$

This control law keeps the substrate concentration constant at a prespecified setpoint $\mathrm{C}_{\mathrm{S}}^{*}$ and equals the exponential feed rate as referred to in the literature survey of the introductory section. The optimal choice of the setpoint (to maximize the final amount of biomass) corresponds with the maximum value of the specific growth rate, which is reached at $\mathrm{C}_{\mathrm{S}} \triangleq \mathrm{C}_{\mathrm{S}, \mu} \equiv \sqrt{\mathrm{K}_{\mathrm{p}} \mathrm{K}_{\mathrm{l}}}$.

In view of generic control algorithms to maximize bi omass production, Åkesson et al. propose an attractive way to obtain on-line detection of the onset of acetate formation in an $\mathrm{E}$. coli fermentation using a standard dissolved oxygen probe (24). The rationale is that, once the acetate formation starts, the oxygen response saturates and is insensitive for short extra feed pulses with glucose. Although not yet reported, the authors daim that a similar approach can be applied to avoid ethanol formation in baker's yeast production. However, we 


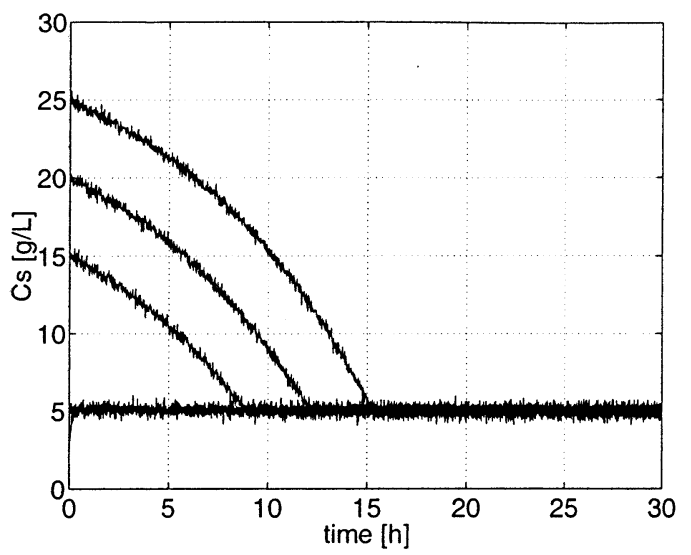

Figure 2. Performance of $C_{S}$ setpoint controller (eq 5) for various initial substrate concentrations. $C_{\mathrm{S}}^{*}=5 \mathrm{~g} / \mathrm{L}$.

address in this work both setpoints on the left flank (to maximize biomass) and unstable setpoints on the right flank (to maximize product formation) of the Haldane kinetics.

As mentioned before, if controller (eq 3) is implemented in open loop, process disturbances nor measurement or modeling errors can be compensated for. Ther efore, some mechanism must be incorporated in the control law (eq 3) to control the tracking error in the presence of disturbances. This is done, e.g., by adding a (nonlinear) linearizing feedback part (25).

2.2. Feedback Linearizing Control. The following closed loop dynamics for the substrate concentration $C_{S}$ is imposed to guarantee the convergence of the controller to the desired setpoint $\mathrm{C}_{\mathrm{S}}^{*}$ (with $\tau_{\mathrm{CS}}[1 / \mathrm{h}]$ a strictly positive tuning factor):

$$
\frac{d\left(C_{s}-C_{S}^{*}\right)}{d t}=-\tau_{C S}\left(C_{s}-C_{S}^{*}\right)
$$

The combination of the closed loop dynamics (eq 4) with the mass balance equation for the substrate concentration (eq 2 ) results in

$$
\mathrm{u}=\frac{\sigma \mathrm{C}_{\mathrm{X}}}{\mathrm{C}_{\mathrm{S}, \text { in }}-\mathrm{C}_{\mathrm{S}}^{*}} \mathrm{~V}-\tau_{\mathrm{CS}} \frac{\mathrm{C}_{\mathrm{S}}-\mathrm{C}_{\mathrm{S}}^{*}}{\mathrm{C}_{\mathrm{S}, \text { in }}-\mathrm{C}_{\mathrm{S}}^{*}} \mathrm{~V}
$$

This linearizing control law (eq 5) can be interpreted as the feedforward optimal control (eq 3) (first term) plus feedback action (second term).

2.3. Simulation Results. All simulations are performed using a continuous time process model and a discrete time control action ( $\Delta T=1 \mathrm{~min}$ ). Between two samples the control action is kept constant. In addition, the on-line measurements of $\mathrm{C}_{\mathrm{S}}$ and $\mathrm{C}_{\mathrm{x}}$ are assumed to be corrupted by (zero mean white) noise. The standard deviation is set equal to $\operatorname{std}\left(C_{X}\right)=0.0625 \mathrm{~g} / \mathrm{L}$ and std$\left(C_{\mathrm{s}}\right)=0.25 \mathrm{~g} / \mathrm{L}$.

The other simulation parameters are $\tau_{\mathrm{CS}}=10 \mathrm{1} / \mathrm{h} ; \mathrm{C}_{\mathrm{S} \text {, in }}$ $=500 \mathrm{~g} / \mathrm{L} ; \mathrm{Y}_{\mathrm{X} / \mathrm{S}}=0.5 ; \mathrm{m}=0.29 \mathrm{1} / \mathrm{h} ; \mathrm{K}_{\mathrm{I}}=1 \mathrm{~g} / \mathrm{L} ; \mathrm{K}_{\mathrm{P}}=100$ $\mathrm{g} / \mathrm{L} ; \mu_{\mathrm{m}}=2.1 \mathrm{1} / \mathrm{h} ; \mathrm{u}_{\max }=1 \mathrm{~L} / \mathrm{h}$. Observe that $\mu$ reaches its maximum at $C_{S}$ equal to $C_{S, u} \equiv \sqrt{K_{1} K_{\mathrm{P}}}=10 \mathrm{~g} / \mathrm{L}$ (see Figure 1).

The ability to stabilize at a desired setpoint starting from different initial substrate concentrations $C_{s}(0)$ is illustrated in Figures 2 and 3. In Figure 2 the setpoint is equal to $C_{\mathrm{S}}^{*}=5 \mathrm{~g} / \mathrm{L}$ (which is on the left flank, i.e., $\mathrm{C}_{\mathrm{S}}^{*}$ $<\mathrm{C}_{\mathrm{S}, u}$ ). In Figure 3 the setpoint is equal to $\mathrm{C}_{\mathrm{S}}^{*}=15 \mathrm{~g} / \mathrm{L}$ (which is on the right flank, i.e., $\mathrm{C}_{\mathrm{S}}^{*}>\mathrm{C}_{\mathrm{s}, u}$ ).

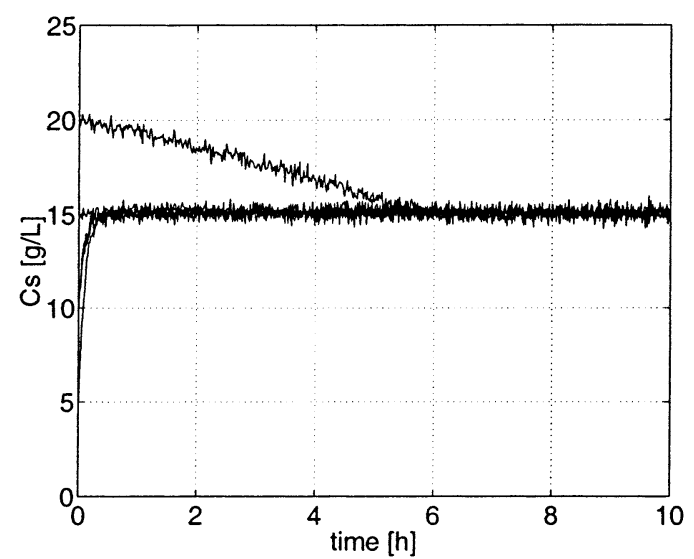

Figure 3. Performance of $C_{s}$ setpoint controller (eq 5) for various initial substrate concentrations. $\mathrm{C}_{\mathrm{S}}^{*}=15 \mathrm{~g} / \mathrm{L}$.

The practical implementation of control law (eq 5) depends on (i) the availability of on-line measurements for both $\mathrm{C}_{\mathrm{S}}$ and $\mathrm{C}_{\mathrm{X}}$ (and $\mathrm{V}$ ), and (ii) full knowledge of the growth kinetics $\mu$ (and thus $\sigma$ ). In the following, these assumptions will be relaxed to a more realistic situation.

\section{On-Line measurements of $\mathbf{C}_{\mathbf{x}}$}

Under the assumption that on-line measurements of the substrate concentration are not available, but only on-line measurements of the biomass concentration $C_{x}$ (and, based on these, on-line estimates of the specific growth rate $\mu$ ) can be supplied (see, e.g., refs 26 and 27), a control law similar to the control law (eq 5) can be derived. The control objective is reformulated from reaching a desired setpoint for the substrate concentration $\mathrm{C}_{\mathrm{S}}^{*}$ to reaching a desired setpoint for the specific growth rate $\mu^{*}$ :

$$
\mathrm{u}=\frac{\sigma \mathrm{C}_{\mathrm{X}}}{\mathrm{C}_{\mathrm{S}, \mathrm{in}}-\mathrm{C}_{\mathrm{S}}^{*}} \mathrm{~V}-\tau_{\mu} \frac{\mu-\mu^{*}}{\mathrm{C}_{\mathrm{S}, \text { in }}-\mathrm{C}_{\mathrm{S}}^{*}} \mathrm{~V}
$$

with $\tau_{\mu}[\mathrm{g} / \mathrm{L}]$ a strictly positive tuning factor.

In the case of monotonic kinetics for $\mu$, eq 6 performs well (26). However, in case of non-monotonic kinetics a setpoint of the specific growth rate $\mu^{*}$ corresponds with two values for the substrate concentration, i.e., the desired setpoint $\mathrm{C}_{\mathrm{S}}^{*}$ and a so-called associated substrate concentration $\mathrm{C}_{\mathrm{s}, \mathrm{a}}^{*}$. Therefore, mechanisms must be incorporated to ensure the convergence to the desired setpoint.

3.1. Analysis of Closed Loop Performance. Starting from the control law (eq 6) and assuming Haldane kinetics (eq 1), after some manipulations the closed loop dynamics of $\mathrm{C}_{\mathrm{S}}$ become

$$
\begin{aligned}
\frac{\mathrm{d}}{\mathrm{dt}}\left(\mathrm{C}_{\mathrm{S}}-\mathrm{C}_{\mathrm{S}}^{*}\right) & =-\tau_{\mu}\left(\mu-\mu^{*}\right) \\
& =-\alpha\left(\mathrm{K}_{\mathrm{P}} \mathrm{K}_{\mathrm{I}}-\mathrm{C}_{\mathrm{S}} \mathrm{C}_{\mathrm{S}}^{*}\right)\left(\mathrm{C}_{\mathrm{S}}-\mathrm{C}_{\mathrm{S}}^{*}\right)
\end{aligned}
$$

with $\alpha$ an unconditionally positive number.

Hence, convergence of the closed loop is determined by the sign of $\left(\mathrm{K}_{\mathrm{p}} \mathrm{K}_{\mathrm{I}}-\mathrm{C}_{\mathrm{S}} \mathrm{C}_{\mathrm{S}}^{*}\right)$. Consequently, the controller (eq 6) will stabilize around the specified setpoint $C_{S}^{*}$ if and only if following condition is met:

$$
\forall \mathrm{t}: \mathrm{C}_{\mathrm{S}}(\mathrm{t})<\frac{\mathrm{K}_{\mathrm{P}} \mathrm{K}_{\mathrm{I}}}{\mathrm{C}_{\mathrm{S}}^{*}}
$$




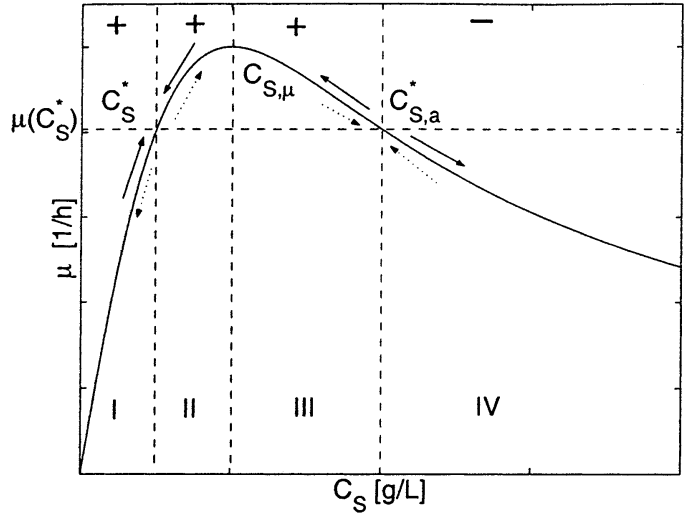

Figure 4. $\mathrm{C}_{\mathrm{S}}^{*}$ setpoint left from $\mathrm{C}_{\mathrm{S}, u}$. Evolution of the specific growth rate starting from different substrate concentration regions (Region I, II, III, or IV). Solid arrows: application of control law (eq 9) with $f=+1$. Dashed arrows: application of control law (eq 9) with $f=-1$. The indicated + or - signs correspond with the sign of factor $f$ in eq 9 for the setpoint considered here.

In addition, since the setpoint is now specified in terms of the specific growth rate, eq 6 tries to stabilize the process around a substrate setpoint concentration corresponding with the specific growth rate setpoint $\mu^{*}$. However, as already mentioned, as a result of the Haldanetype kinetics assumption, the stabilized concentration will be either $\mathrm{C}_{\mathrm{S}}^{*}$ or its associated concentrati on $\mathrm{C}_{\mathrm{S}, \mathrm{a}}^{*}$, depending on which of these concentrations is encountered first during the process evolution. Figures 4 and 5 illustrate the above observations.

Left Flank Substrate Concentration Setpoint $C_{\mathrm{S}}^{*}$ $<\mathbf{C}_{\mathbf{s}_{, u}}$ (Figure 4). The substrate concentration space is subdivided in four regions by the values of $\mathrm{C}_{\mathrm{S}}^{*}, \mathrm{C}_{\mathrm{S}, u}$, and $\mathrm{C}_{\mathrm{S}, \mathrm{a}}^{*}$, respectively. Depending on the location of the initial substrate concentration (representing the value of $C_{S}$ after a process disturbance) the evolution of the specific growth rate (when applying eq 6 ) is indicated by the solid arrows. Region I, delineated by $\mathrm{C}_{\mathrm{S}}^{*}$, is characterized by a specific growth rate that is smaller than the setpoint value $\mu^{*}$ but increasing toward the $\mu^{*}$ setpoint corresponding with the desired $\mathrm{C}_{S}^{*}$ value. In Region II, the specific growth rate is larger than the setpoint $\mu^{*}$ and decreasing toward the $\mu^{*}$ setpoint corresponding with the desired $\mathrm{C}_{\mathrm{S}}^{*}$ value. In Region III, the specific growth rate is larger than the setpoint $\mu^{*}$ and increasing. Again, $\mathrm{C}_{\mathrm{S}}^{*}$ will be reached (and stabilized) after a certain time period. Finally, Region IV is characterized by a specific growth rate that is smaller than the setpoint and decreasing (due to violation of constraint in eq 8). As such, $\mathrm{C}_{\mathrm{S}}^{*}$ will never be reached.

Hence, starting from substrate concentration values contained in Regions I, II, or III, the system will be stabilized around the desired l eft flank setpoint (indicated with a plus sign). Only when starting from Region IV (i.e., $C_{S}$ values far away from the $C_{S}^{*}$ setpoint) will the desired setpoint not be reached, indicated by the minus sign.

Right Flank Substrate Concentration Setpoint $\mathbf{C}_{\mathbf{S}}^{*}>\mathbf{C}_{\mathbf{S}, u}$ (Figure 5). Similar to the $\mathrm{C}_{\mathrm{S}}^{*}<\mathrm{C}_{\mathrm{S}, \mu}$ case, the substrate concentration space is subdivided into four regions by the values of $\mathrm{C}_{\mathrm{s}, \mathrm{a}}^{*}, \mathrm{C}_{\mathrm{s}, u}$, and $\mathrm{C}_{\mathrm{s}}^{*}$, respectively. Straightforward application of the control law (eq 6) results in a specific growth rate behavior as indicated by the solid arrows. Region I is characterized by a specific growth rate that is smaller than the setpoint $\mu^{*}$ and

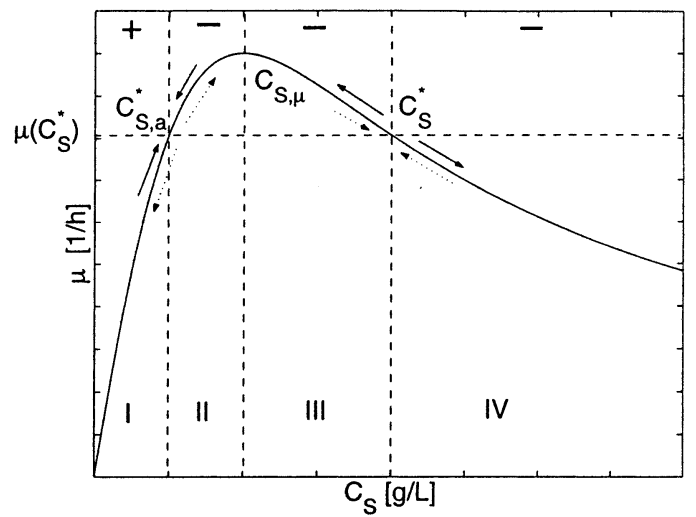

Figure 5. $\mathrm{C}_{\mathrm{S}}^{*}$ setpoint right from $\mathrm{C}_{\mathrm{S}, \mu}$. Evolution of the specific growth rate starting from different substrate concentration regions (Region I, II, III, or IV). Solid arrows: application of control law (eq 9) with $f=+1$. Dashed arrows: application of control law (eq 9) with $f=-1$. The indicated + or - signs correspond with the sign of factor $f$ in eq 9 for the setpoint considered here

increasing. Unfortunately, controller action stops when $\mathrm{C}_{\mathrm{S}, \mathrm{a}}^{*}$ is reached since the specified setpoint $\mu^{*}$ is met. Region II illustrates that the specific growth rate is larger than the setpoint $\mu^{*}$ and decreasing toward the setpoint $\mu^{*}$ corresponding with $\mathrm{C}_{\mathrm{S}, \mathrm{a}}^{*}$. In Region III, the specific growth rate is larger than the setpoint $\mu^{*}$ and increasing. Again, the system will be stabilized around the $\mathrm{C}_{\mathrm{s}}^{*}$ value. Finally, Region IV is characterized by a specific growth rate that is smaller than the setpoint $\mu^{*}$ and decreasing due to the violation of the constraint in eq 8 .

It can be concluded that, with the control law in eq 6, the system cannot be stabilized around the desired right flank setpoint concentration $\mathrm{C}_{\mathrm{S}}^{*}$. In fact, eq 6 will instead stabilize the system around the associated left flank concentration $\mathrm{C}_{\mathrm{S}, \mathrm{a}}^{*}$ (which is equal to $\mathrm{K}_{\mathrm{P}} \mathrm{K}_{\mathrm{I}} / \mathrm{C}_{\mathrm{S}}^{*}$ ) for initial values within the close neighborhood of $\mathrm{C}_{\mathrm{S}, \mathrm{a}}^{*}$, i.e., $\mathrm{Re}$ gions I, II, or III. Starting from Region IV' substrate concentrations, the system will not be stabilized at all (not at $\mathrm{C}_{\mathrm{S}}^{*}$ nor at $\mathrm{C}_{\mathrm{S}, \mathrm{a}}^{*}$ ). Note that only in Region I is the evolution of the specific growth rate in the right (i.e., upward) direction, indicated with the plus sign.

These results are in general agreement with the stability analysis of the open loop exponential fed-batch culture with $\mathrm{H}$ aldanetype kinetics performed by Yamane et al. (28) and Bastin and Dochain (29). Setpoints on the left flank of the non-monotonic kinetics are stable, i.e., small fluctuations around the setpoint do not cause the substrate concentration to diverge from the setpoint, whereas setpoints on the right flank are unstable since small variations cause the substrate concentrations to deviate more and more from the setpoint.

To compensate for (i) the possibly negative sign of the factor $\left(\mathrm{K}_{\mathrm{P}} \mathrm{K}_{\mathrm{I}}-\mathrm{C}_{\mathrm{S}} \mathrm{C}_{\mathrm{S}}^{*}\right)$ (violation of the constraint in eq 8) and (ii) convergence to the associated substrate concentration $\mathrm{C}_{\mathrm{S}, \mathrm{a}}^{*}$ instead of to the desired setpoint $\mathrm{C}_{\mathrm{S}}^{*}$, an adaptation to the control law (eq 6 ) is made by introducing a factor $\mathrm{f}$, which precedes the driving term $\left(\mu-\mu^{*}\right)$ :

$$
\mathrm{u}_{\mathrm{f}}=\frac{\sigma \mathrm{C}_{\mathrm{x}}}{\mathrm{C}_{\mathrm{S}, \mathrm{in}}-\mathrm{C}_{\mathrm{S}}^{*}} \mathrm{~V}-\mathrm{f} \tau_{\mu} \frac{\mu-\mu^{*}}{\mathrm{C}_{\mathrm{S}, \mathrm{in}}-\mathrm{C}_{\mathrm{S}}^{*}} \mathrm{~V}
$$

The factor $f$ can switch from +1 to -1 , or vice versa, depending on (i) the location of the setpoint, i.e., on the left or right flank, and (ii) the region in which the instantaneous substrate concentration is located. The 

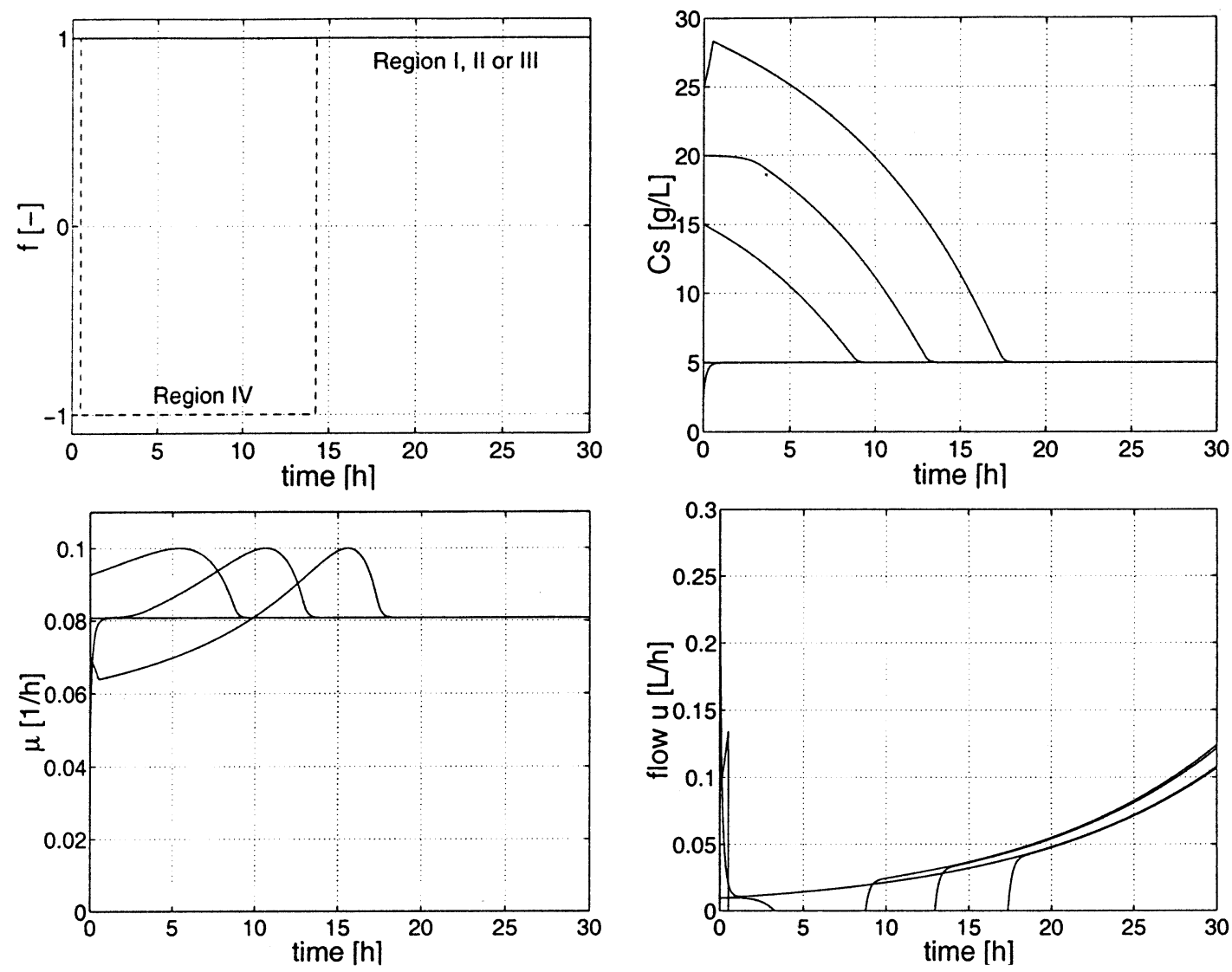

Figure 6. $\mu$ setpoint controller (with switch factor $\mathrm{f}$ ) (eq 9) with instantaneous knowledge of $\mu$ for various initial substrate concentrations: $\mu^{*}=\mu\left(\mathrm{C}_{\mathrm{S}}^{*}\right)$ with $\mathrm{C}_{\mathrm{S}}^{*}=0.5 \mathrm{C}_{\mathrm{S}, \mu}$. Upper left plot: evolution of switch factor $\mathrm{f}$. U pper right plot: substrate concentration $\mathrm{C}_{\mathrm{s}}$ with respect to time. Lower left plot: specific growth rate $\mu$ with respect to time. Lower right plot: flow rate $\mathrm{u}$ with respect to time.

rationale of the switch algorithm can be inferred from Figures 4 and 5 for a setpoint $\mathrm{C}_{\mathrm{S}}^{*}$ smaller and larger than the $\mathrm{C}_{\mathrm{s}, u}$ value, respectively.

Left Flank Substrate Concentration Setpoint $C_{S}^{*}$ $<\mathbf{C}_{\mathbf{s}, u}$ (Figure 4). The solid arrows indicate the evolution of the specific growth rate if in all regions a factor $f$ equal to +1 is applied (corresponding with straightforward application of eq 6). As explained in the former section, a substrate concentration lying in Region I, II, or III will converge to the desired left flank setpoint. In Region IV, however, a decreasing specific growth rate $\mu$ and therefore an increasing substrate concentration is induced if a value of +1 is assigned to $f$. Therefore, the factor $f$ has to switch to -1 (dashed arrow) in Region IV. Once the specific growth rate enters the regions of attraction (Regions I, II, III), f has to switch back to +1 (solid arrows). Hence, the appropriate sign of the factor $f$ in each region corresponds with the plus or minus signs introduced in the previous section.

Right Flank Substrate Concentration Setpoint $\mathbf{C}_{\mathbf{s}}^{*}>\mathbf{C}_{\mathbf{s}, u}$ (Figure 5). As explained before, eq 6, which is equivalent to eq 9 with $f$ equal to +1 , tries to stabilize the system around the left flank associated setpoint concentration $\mathrm{C}_{\mathrm{S}, \mathrm{a}}^{*}$ (indicated by the solid arrows) instead of around the desired right flank setpoint $\mathrm{C}_{\mathrm{S}}^{*}$. A far better evolution of the system is obtained when assigning the value of -1 to the factor $f$ (indicated by the dashed arrows). However, the specific growth rate in Region I becomes then smaller than the setpoint $\mu^{*}$ and decreasing, whereas it was increasing (as it should be) with an $f$ value of +1 . Therefore, the factor $f$ has to switch to +1 in Region I (solid arrow). Once the specific growth rate enters the regions of attraction (Regions II, III, IV) f has to switch back to -1 (dashed arrows). As can be seen, the sign of the factor $f$ corresponds with the plus or minus signs attributed to the different regions in the previous section.

When initializing the switch factor $f$ to +1 for a left flank substrate concentration setpoint and to -1 for a right flank substrate concentration setpoint, the following control al gorithm is proposed.

(a) Determination of factor $f$

$$
\begin{aligned}
\text { if } \mathrm{C}_{\mathrm{S}}^{*}< & \mathrm{C}_{\mathrm{S}, \mu} \\
& \text { initial } \mathrm{f}=1 \\
& \text { if } \mu<\mu^{*} \text { and } \mu(\mathrm{t})-\mu(\mathrm{t}-\Delta \mathrm{t})<0 \\
& \text { then } \mathrm{f}=-1 \text { (Region IV) } \\
& \text { else } \mathrm{f}=+1(\text { Region } \mathrm{I}, \mathrm{II}, \mathrm{III}) \\
& \text { if } \mu>\mu^{*} \text { and } \mathrm{f}=-1 \\
& \text { then } \mathrm{f}=+1 \\
\text { if } \mathrm{C}_{\mathrm{S}}^{*}>\mathrm{C}_{\mathrm{S}, \mu} & \\
& \text { initial } \mathrm{f}=-1 \\
& \text { if } \mu<\mu^{*} \text { and } \mu(\mathrm{t})-\mu(\mathrm{t}-\Delta \mathrm{t})<0 \\
& \text { then } \mathrm{f}=+1(\text { Region } \mathrm{I}) \\
& \text { else } \mathrm{f}=-1(\text { Region II, III, IV) } \\
& \text { if } \mu>\mu^{*} \text { and } \mathrm{f}=+1 \\
& \text { then } \mathrm{f}=-1
\end{aligned}
$$



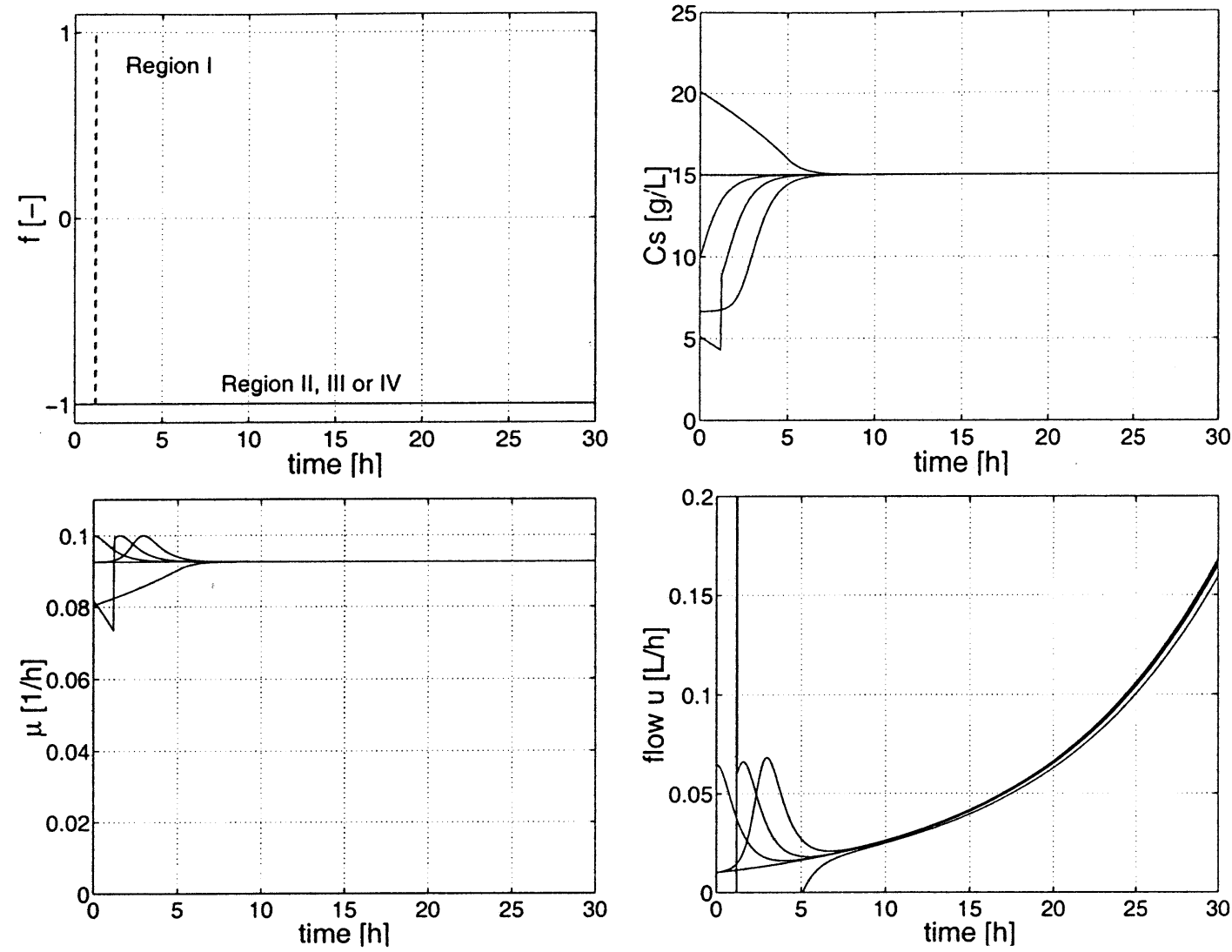

Figure 7. $\mu$ setpoint controller (with switch factor f) (eq 9) with instantaneous knowledge of $\mu$ for various initial substrate concentrations: $\mu^{*}=\mu\left(\mathrm{C}_{\mathrm{S}}^{*}\right)$ with $\mathrm{C}_{\mathrm{S}}^{*}=1.5 \mathrm{C}_{\mathrm{S}, \mu}$. Upper left plot: evolution of switch factor $\mathrm{f}$. U pper right plot: substrate concentration $\mathrm{C}_{\mathrm{s}}$ with respect to time. Lower left plot: specific growth rate $\mu$ with respect to time. Lower right plot: flow rate $u$ with respect to time.

(b) Calculation of flow rate $u$

$$
\begin{aligned}
\mathrm{u}_{\mathrm{f}}= & \frac{\sigma \mathrm{C}_{\mathrm{X}} \mathrm{V}}{\mathrm{C}_{\mathrm{S}, \text { in }}-\mathrm{C}_{\mathrm{S}}^{*}}-\mathrm{f}_{\mu} \frac{\mu-\mu^{*}}{\mathrm{C}_{\mathrm{S}, \mathrm{in}}-\mathrm{C}_{\mathrm{S}}^{*}} \mathrm{~V} \\
& \text { if } \mathrm{u}_{\mathrm{f}}<0 \\
& \text { then } \mathrm{u}=0 \\
& \text { else } \mathrm{u}=\mathrm{u}_{\mathrm{f}} \\
& \text { if } \mathrm{u}_{\mathrm{f}}>\mathrm{u}_{\max } \\
& \text { then } \mathrm{u}=\mathrm{u}_{\max } \\
& \text { else } \mathrm{u}=\mathrm{u}_{\mathrm{f}}
\end{aligned}
$$

$\Delta \mathrm{t}$ is the time period during which the increasing or decreasing tendency of the specific growth rate $\mu$ must be detected. An important implication of the algorithm is therefore that, only after a time delay of $\Delta t$, the controller can counteract deviating substrate concentrations.

The performance of controller eq 9 and the switch algorithm (assuming instantaneous knowledge of the specific growth rate $\mu$ ) is illustrated in Figures 6 and 7 for a setpoint smaller than $\mathrm{C}_{\mathrm{s}, u}$, e.g., $\mathrm{C}_{\mathrm{S}}^{*}=0.5 \mathrm{C}_{\mathrm{s}, u}$ (numerical value $5 \mathrm{~g} / \mathrm{L}$ ) and for a setpoint larger than $\mathrm{C}_{\mathrm{s}, u}$, e.g., $\mathrm{C}_{\mathrm{S}}^{*}=1.5 \mathrm{C}_{\mathrm{s}, u}$ (numerical value $15 \mathrm{~g} / \mathrm{L}$ ), respectively. Prior to any optimal tuning of the controller, $\tau_{\mu}$ is set equal to $500 \mathrm{~g} / \mathrm{L}$ and no noise on the measurements (or estimates) is taken into account. For the setpoint smaller than $\mathrm{C}_{\mathrm{s}, u}$, i.e., $\mathrm{C}_{\mathrm{S}}^{*}=5 \mathrm{~g} / \mathrm{L}$ (Figure 6) eq 9 performs well even for starting values larger than the numerical value of the associated substrate concentration $\mathrm{C}_{\mathrm{S}, \mathrm{a}}^{*}(20 \mathrm{~g} / \mathrm{L})$ (Region IV), illustrated with the (initial) value of $25 \mathrm{~g} / \mathrm{L}$. Once the increasing substrate concentration in this region is detected by a decrease of the specific growth rate, the $f$ value is switched to -1 (inducing a batch period) until Region III is attained.

Convergence and stabilization is also guaranteed for a setpoint larger than $\mathrm{C}_{\mathrm{s}, u}$, i.e., $\mathrm{C}_{\mathrm{s}}^{*}=15 \mathrm{~g} / \mathrm{L}$ (Figure 7), illustrated with (initial) values of $5 \mathrm{~g} / \mathrm{L}$ (Region I), $10 \mathrm{~g} / \mathrm{L}$ (boundary between Region II and III), and $20 \mathrm{~g} / \mathrm{L}$ (Region IV). Note that for Region I values, the substrate concentration first decreases. Once the decreasing trend of the corresponding specific growth rate is detected, $\mathrm{f}$ switches to +1 (resulting in a short maximum feeding period) until Region II is attained.

3.2. Tuning of the Controller. To assess the performance of eq 9, i.e., to evaluate the impact of the sel ected tuning parameter $\tau_{\mu}$ on convergence to the specified substrate concentration setpoint, the total period is calculated during which the (estimated) specific growth rate remains in the close neighborhood of the specific growth rate setpoint (corresponding to the substrate concentration setpoint). This period is expressed as a sum of durations $\left[t_{i+1}-t_{i}\right]$ and is compared with the total fermentation time $t_{f}$

$$
\mathrm{E}_{\mathrm{C}}=\frac{\sum\left[\mathrm{t}_{\mathrm{i}+1}-\mathrm{t}_{\mathrm{i}}\right]}{\mathrm{t}_{\mathrm{f}}} \text { for which }\left|\mu(\mathrm{t})-\mu^{*}\right|<\epsilon_{\mu}
$$

with $\epsilon_{\mu}$ equal to $0.0051 / \mathrm{h}$ in this case study.

To mimic realistic estimated $\mu$ values obtained from noisy biomass concentration measurements (which will 

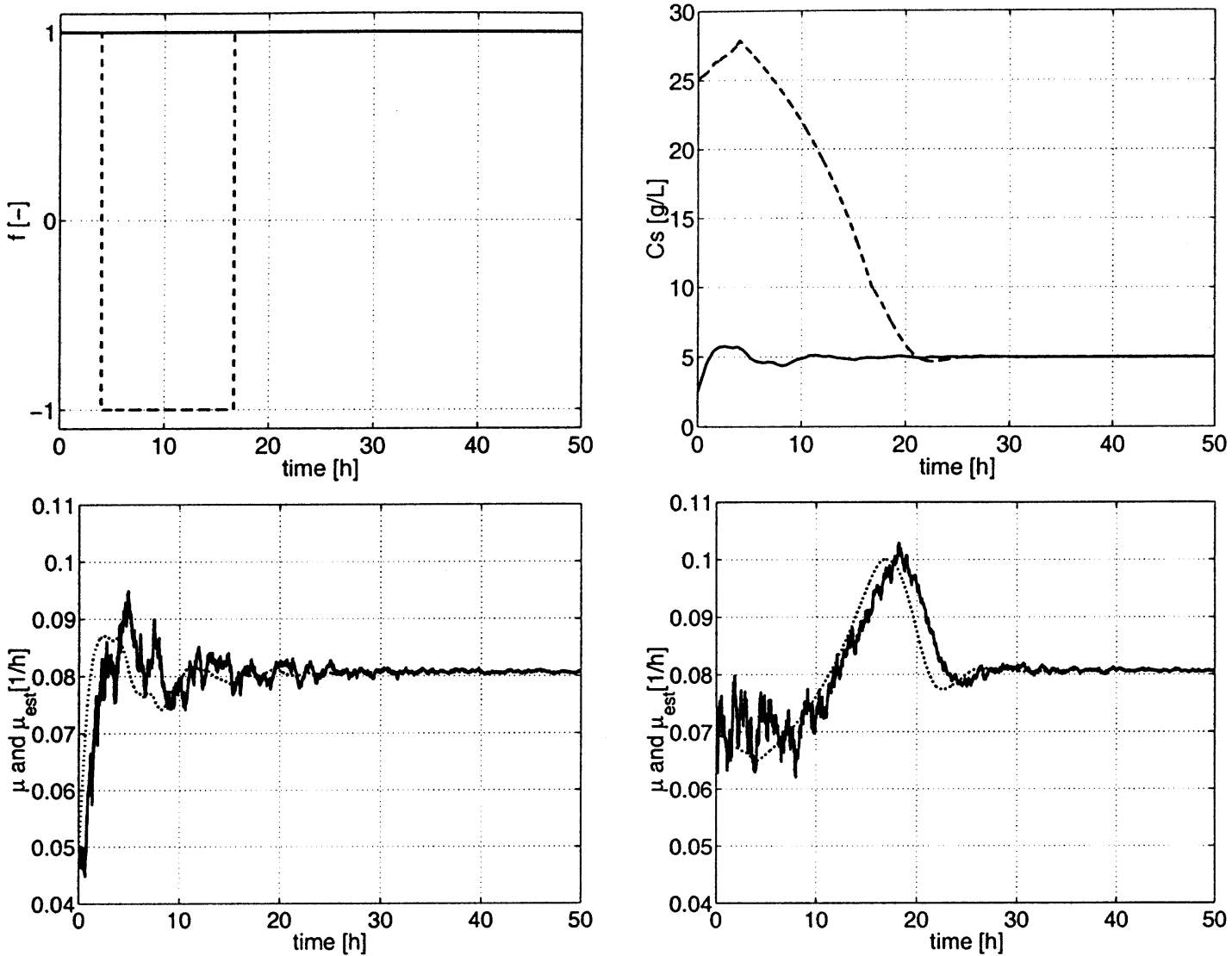

Figure 8. Performance of $\mu$ setpoint controller (eq 9) with observer for $\mu^{*}=\mu\left(\mathrm{C}_{\mathrm{S}}^{*}\right)=0.081 / \mathrm{h}$ with $\mathrm{C}_{\mathrm{S}}^{*}=5 \mathrm{~g} / \mathrm{L}$ for $\mathrm{C}_{\mathrm{S}}(0)=2.5 \mathrm{~g} / \mathrm{L}$ (solid line) and $\mathrm{C}_{\mathrm{s}}(0)=25 \mathrm{~g} / \mathrm{L}$ (dashed line). $\tau_{\mu}=75 \mathrm{~g} / \mathrm{L}$ and $\lambda=-1.4 \mathrm{l} / \mathrm{h}$. U pper left plot: evolution of switch factor $\mathrm{f}$. Upper right plot: substrate concentration $C_{s}$ with respect to time. Lower left plot: estimated specific growth rate $\hat{\mu}$ (solid line) and instantaneous specific growth rate $\mu\left(C_{s}\right)$ (dotted line) with respect to time for $C_{s}(0)=2.5 \mathrm{~g} / \mathrm{L}$. Lower right plot: estimated specific growth rate $\hat{\mu}$ (solid line) and instantaneous specific growth rate $\mu\left(\mathrm{C}_{\mathrm{s}}\right)$ (dotted line) with respect to time for $\mathrm{C}_{\mathrm{s}}(0)=25 \mathrm{~g} / \mathrm{L}$. The on-line measurements of $C_{x}$ are assumed to be corrupted by (zero mean white) noise: $\operatorname{std}\left(C_{x}\right)=0.0625 \mathrm{~g} / \mathrm{L}$.

be discussed in the next subsection), the instantaneous $\mu$ values (cal culated as $\mu\left(C_{s}\right)$ with eq 1 ) are corrupted with zero mean white noise $(\operatorname{std}(\mu)=0.005)$. To account for this noise, the decision to switch the f factor when the specific growth rate is decreasing and below the setpoint will be taken when the (estimated) specific growth rate is smaller than $75 \%$ of the $\mu^{*}$ setpoint value.

Two major restrictions hamper the unique determination of an optimal $\tau_{\mu}$ tuning parameter. First, the optimal $\tau_{\mu}$ value depends on the selected class of initial substrate concentration (corresponding with the before mentioned regions), since different controller actions are induced (i.e., maximum feeding, singular feeding or batch operation) when starting from different classes of initial substrate concentrations. Second, as a result of the noisy specific growth rate estimates, a single performance evaluation (for a specific class of initial substrate concentrations) will not be representative. Therefore, for each class of initial substrate concentrations each $\tau_{\mu}$ value is evaluated 10 times to obtain a representative mean performance value and among these the optimal value (corresponding with the highest value of $\mathrm{E}_{\mathrm{C}}$ ) is selected. At this point each class of initial substrate concentrations has its optimal $\tau_{\mu}$ value. From this list of optimal values an appropriate compromise value is selected to ensure acceptable (but perhaps not the best) performance for all operating conditions.

Following the above-mentioned procedure, the optimal tuning parameter $\tau_{\mu}$ is selected equal to $200 \mathrm{~g} / \mathrm{L}$ for the left flank substrate concentration setpoint $\left(C_{\mathrm{S}}^{*}=5 \mathrm{~g} / \mathrm{L}\right)$ as well as for the right flank substrate concentration setpoint $\left(\mathrm{C}_{\mathrm{S}}^{*}=15 \mathrm{~g} / \mathrm{L}\right)$.

3.3. $\mathbf{C}_{\mathbf{x}}$-Based $\mu$-Observer. In this subsection the dynamics of an observer providing estimates of $\mu$ on the basis of on-line biomass measurements is introduced. Online measurements of the biomass concentration can be provided by, e.g., the Biomass M onitor (BM 214-M, Aber Instruments LTD, Aberystwyth, UK (30). This in situ monitor relates the capacitance of the medium with the viable biomass concentration. The fol lowing state-observerbased estimator for the specific growth rate is proposed (for more details see ref 29):

$$
\begin{gathered}
\frac{\mathrm{d} \widehat{\mathrm{C}_{\mathrm{X}}}}{\mathrm{dt}}=\hat{\mu} \mathrm{C}_{\mathrm{x}}-\frac{\mathrm{u}}{\mathrm{V}} \mathrm{C}_{\mathrm{x}}-\omega\left(\mathrm{C}_{\mathrm{X}}-\widehat{\mathrm{C}_{\mathrm{X}}}\right) \\
\frac{\mathrm{d} \hat{\mu}}{\mathrm{dt}}=\gamma \mathrm{C}_{\mathrm{x}}\left(\mathrm{C}_{\mathrm{X}}-\widehat{\mathrm{C}_{\mathrm{X}}}\right)
\end{gathered}
$$

where ${ }^{\wedge}$ denotes an estimated quantity and $\omega[1 / \mathrm{h}]$ and $\gamma\left[\mathrm{L}^{2} /\left(\mathrm{g}^{2} \mathrm{~h}^{2}\right)\right]$ are tuning functions. When selecting these tuning functions equal to $\omega=2 \lambda$ and $\gamma=\lambda^{2} / C_{x}{ }^{2}$, the dynamics of the corresponding error system are governed by the (double) eigenvalue $-\lambda[1 / \mathrm{h}]$. Fine-tuning of the observer reduces to selecting a suitable value for $\lambda$ to ensure a tradeoff between convergence rate and noise sensitivity (see next section).

3.4. Tuning of the Combined $\mathrm{C}_{\mathrm{x}}$-Based $\mu$-Observer and Controller. Tuning of the controller involving $C_{x}$ measurements and $\mu$ estimates is an iterative procedure 

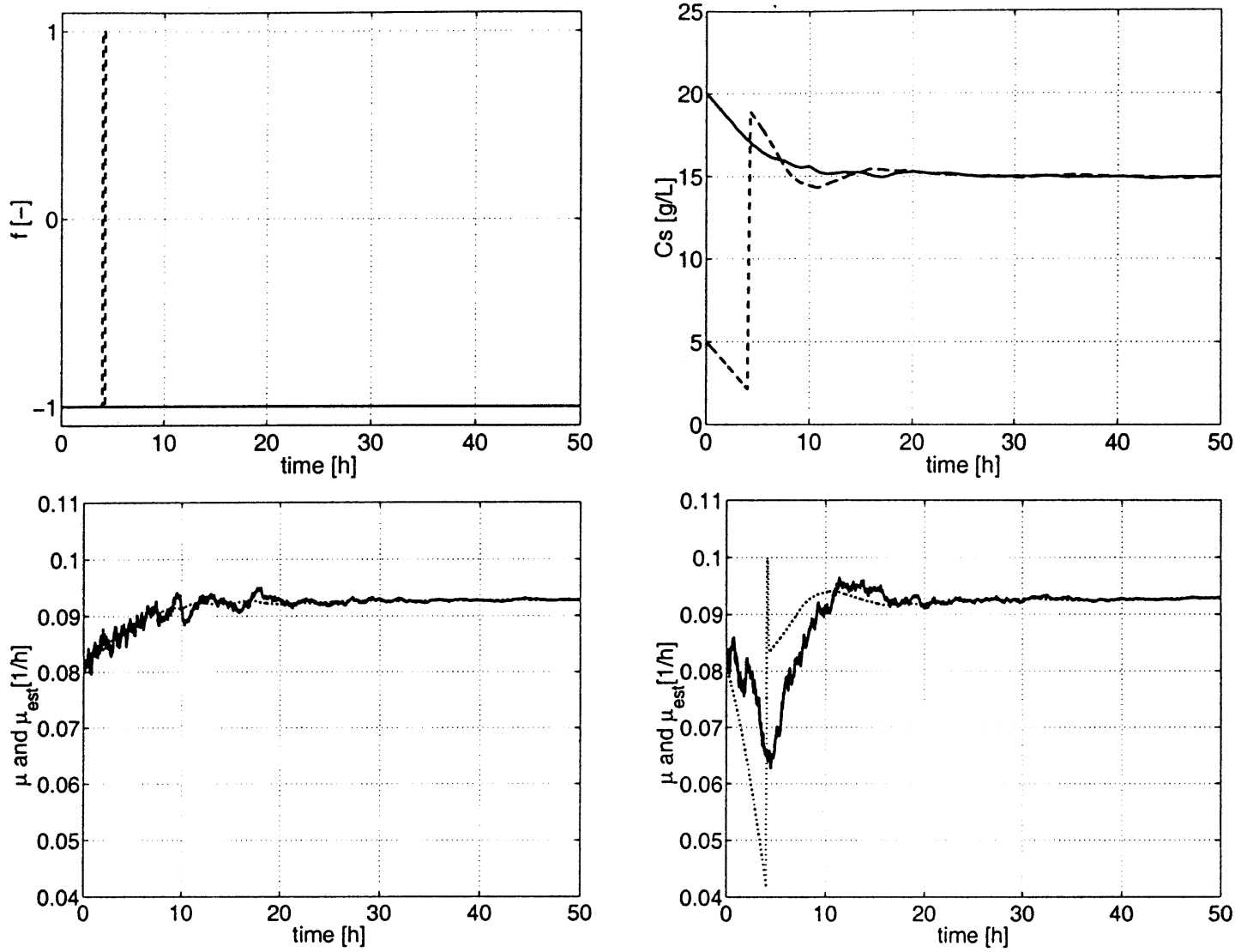

Figure 9. Performance of $\mu$ setpoint controller (9) with observer for $\mu^{*}=\mu\left(\mathrm{C}_{\mathrm{S}}^{*}\right)=0.093 \mathrm{1} / \mathrm{h}$ with $\mathrm{C}_{\mathrm{S}}^{*}=15 \mathrm{~g} / \mathrm{L}$ for $\mathrm{C}_{\mathrm{S}}(0)=20 \mathrm{~g} / \mathrm{L}(\mathrm{solid}$ line) and $C_{S}(0)=5 \mathrm{~g} / \mathrm{L}$ (dashed line). $\tau_{\mu}=100 \mathrm{~g} / \mathrm{L}$ and $\lambda=-1 \mathrm{l} / \mathrm{h}$. Upper left plot: evolution of switch factor $\mathrm{f}$. U pper right plot: substrate concentration $C_{s}$ with respect to time. Lower left plot: estimated specific growth rate $\hat{\mu}$ (solid line) and instantaneous specific growth rate $\mu\left(C_{S}\right)$ (dotted line) with respect to time for $C_{s}(0)=20 \mathrm{~g} / \mathrm{L}$. L ower right plot: estimated specific growth rate $\hat{\mu}$ (solid line) and instantaneous specific growth rate $\mu\left(\mathrm{C}_{\mathrm{s}}\right)$ (dotted line) with respect to time for $\mathrm{C}_{\mathrm{s}}(0)=5 \mathrm{~g} / \mathrm{L}$. The on-line measurements of $C_{X}$ are assumed to be corrupted by (zero mean white) noise: $s t d\left(C_{X}\right)=0.0625 \mathrm{~g} / \mathrm{L}$.

in which (i) the observer tuning parameter $\lambda$ has to be selected to ensure fast convergence of the estimated biomass concentration to the measured bi omass concentration while avoiding high noise sensitivity, and (ii) the controller tuning parameter $\tau_{\mu}$ has to guarantee proper convergence to the substrate concentration setpoint.

Tuning of the Observer. To quantify observer convergence the sum of squared differences between the measured and the estimated values of the biomass concentration is considered:

$$
\mathrm{E}_{\mathrm{O}, 1}=\sum_{\mathrm{k}=1}^{\mathrm{N}}\left(\widehat{\mathrm{C}_{\mathrm{X}, \mathrm{k}}}-\mathrm{C}_{\mathrm{X}, \mathrm{k}}\right)^{2}
$$

with $C_{X, k}$ and $\widehat{C_{X, k}}$ the value of the biomass concentration measurement and its estimate at sampling time $\mathrm{k}$, and $\mathrm{N}$ the final fermentation time.

Noise sensitivity of the observer is quantified by the sum of squared differences between two subsequent specific growth rate estimates:

$$
\mathrm{E}_{\mathrm{O}, 2}=\sum_{\mathrm{k}=1}^{\mathrm{N}-1}\left(\hat{\mu}_{\mathrm{k}+1}-\hat{\mu}_{\mathrm{k}}\right)^{2}
$$

with $\hat{\mu}_{\mathrm{k}+1}$ and $\hat{\mu}_{\mathrm{k}}$ the specific growth rate estimates at sampling time $\mathrm{k}+1$ and $\mathrm{k}$, respectively.

The tradeoff between convergence and noise sensitivity is realized by minimizing a weighted sum of the previous observer performance measures:

$$
\mathrm{E}_{\mathrm{O}, \mathrm{tot}}=\mathrm{E}_{\mathrm{O}, 1}+\phi \mathrm{E}_{\mathrm{O}, 2}
$$

with $\phi\left[g^{2} h^{2} / L^{2}\right]$ a user-defined weighting factor.

Again, the optimal $\lambda$ depends on the class of initial substrate concentrations and a suitable mean value has to be selected.

Iterative Tuning of the Combined $\mathrm{C}_{\mathrm{x}}$-Based $\mu$-Observer and Controller. For each initial substrate concentration class, data to tune the observer is obtained by fixing the $\tau_{\mu}$ value to the optimal value selected following the above-introduced controller tuning procedure and sel ecting a relatively large value of $\lambda$, e.g., $\lambda=$ $-31 / h$. Once an appropriate (mean) $\lambda$ value, valid for all initial substrate concentration classes, is obtained through evaluation of cost (eq 12) in which the $\phi$ value is set equal to $10 \mathrm{~g}^{2} \mathrm{~h}^{2} / \mathrm{L}^{2}$, a reevaluation of $\tau_{\mu}$ is performed. With the resulting $\tau_{\mu}$ value, the $\lambda$ value is re-optimized. Once the new $\lambda$ value corresponds with the previously obtained value, the iterative procedure is stopped.

3.5. Results. The optimal tuning parameters for a substrate concentration setpoint smaller than the $\mathrm{C}_{\mathrm{s}, u}$ value are equal to $\tau_{\mu}=75 \mathrm{~g} / \mathrm{L}$ and $\lambda=-1.4 \mathrm{l} / \mathrm{h}$ and for a substrate concentration setpoint larger than the $\mathrm{C}_{\mathrm{s}, u}$ value, they are equal to $\tau_{\mu}=100 \mathrm{~g} / \mathrm{L}$ and $\lambda=-1 \mathrm{l} / \mathrm{h}$. Figures 8 and 9 illustrate the performance of the combined $C_{X}$-based $\mu$-observer for a setpoint on the left and right flank, respectively. Apart from the very smooth transition to the setpoint, the desired switch of the factor 
$\mathrm{f}$ in the regions where the (estimated) specific growth rate is smaller than the setpoint and decreasing is clearly demonstrated. Note, however, that because of the noisy estimates of the specific growth rate, the time to detect undesired behavior of the specific growth rate has increased to almost $5 \mathrm{~h}$. This time delay can become critical for processes in which low substrate concentrations are involved and right flank setpoints $\mathrm{C}_{\mathrm{S}}^{*}$ are selected.

3.6. Asymptotic $\mathbf{C}_{\mathrm{x}}$-Based $\mathbf{C}_{\mathrm{s}}$-Observer. To overcome the lack of on-line measurements of the substrate concentration $\mathrm{C}_{\mathrm{S}}$ and to avoid the switch algorithm as introduced in the previous sections, an alternative approach could be to construct an additional observer for the substrate concentration based on the available measurements, i.e., the bi omass concentration in this study. Inspired by the asymptotic $\mathrm{C}_{\mathrm{X}}$-based $\mathrm{C}_{\mathrm{S}}$-observer proposed by Bastin and Dochain (29), an additional variable $Z$ is introduced:

$$
\mathrm{Z}=\mathrm{Y}_{\mathrm{X} / \mathrm{S}} \mathrm{C}_{\mathrm{S}}+\mathrm{C}_{\mathrm{X}}
$$

Given the fact that (i) the maintenance coefficient is assumed to be known and (ii) the biomass concentration can be measured on-line, the dynamics of the auxiliary variable $Z$ can be written as follows (see eq 2 ):

$$
\frac{d Z}{d t}=-\frac{u}{V} Z+\frac{u}{V} Y_{x / S} C_{S, i n}-Y_{x / S} m C_{x}
$$

The substrate concentration can then be estimated by means of following equations:

$$
\begin{gathered}
\frac{d \hat{Z}}{d t}=-\frac{u_{\hat{Z}}}{V}+\frac{u_{V}}{V} Y_{x / S} C_{S, i n}-Y_{X / S} m C_{X} \\
\widehat{C_{S}}=\frac{1}{Y_{x / S}}\left(\hat{Z}-C_{X}\right)
\end{gathered}
$$

Combined with the $\mathrm{C}_{\mathrm{X}}$-based $\mu$-observer, as described in section 3.3, the following control law performs well (results not shown):

$$
\mathrm{u}=\frac{\left(\frac{\hat{\mu}}{\mathrm{Y}_{\mathrm{X} / \mathrm{S}}}+\mathrm{m}\right) \mathrm{C}_{\mathrm{X}}}{\mathrm{C}_{\mathrm{S}, \mathrm{in}}-\mathrm{C}_{\mathrm{S}}^{*}} \mathrm{~V}-\tau_{\mathrm{CS}} \frac{{\widehat{\mathrm{C}_{\mathrm{S}}}}_{\mathrm{C}_{\mathrm{S}, \mathrm{in}}-\mathrm{C}_{\mathrm{S}}^{*}} \mathrm{~V}}{\mathrm{~S}}
$$

Still, this $\mathrm{C}_{\mathrm{X}}$-based $\mathrm{C}_{\mathrm{s}}$-observer is not a valid alternative for the stabilization of non-monotonic fed-batch processes, given the asymptotic convergence features of the observer. As opposed to exponential observers, the rate of convergence toward the real value of the substrate concentration cannot be adjusted. Indeed, the convergence rate is completely determined by the value of the dilution rate $\mathrm{D} \equiv \mathrm{u} N$ (see eq 14 ), which is most often not completely at the disposal of the user but determined by the experimental setup.

\section{Conclusions}

In this paper, the design of a feedback control law is discussed that forces the substrate concentration to reach a prespecified value in a fed-batch microbial growth process when non-monotonic growth kinetics apply. N onmonotonic kinetics imply a nonunique relationship between $\mu$ and $C_{s}$, i.e., one value of $\mu$ corresponds with two values of $C_{s}$. A practical example is the baker's yeast fermentation process for which a Haldane-type kinetics can be assumed due to the possible inhibition by ethanol.
If measurements of the substrate concentrations $C_{S}$ and biomass concentration $C_{x}$ are available (possibly corrupted by zero mean white noise), one can construct a controller (control law, eq 5) that performs well for each possible setpoint of $\mathrm{C}_{\mathrm{S}}$ starting from an arbitrary (initial) value of the substrate concentration.

If measurements of the substrate concentration $C_{s}$ are not available, but on-line values for the biomass concentration $C_{x}$ (from, e.g., the Biomass Monitor or from optical density measurements) and, based on these, on-line estimates of the specific growth rate $\mu$ can be obtained, a controller can be designed on the basis of these $\mu$ and $C_{x}$ values (control law, eq 9). By introducing a switch factor $\mathrm{f}$ the above-mentioned complexity inherent to nonmonotonic kinetics is surmounted.

The developed controller is indeed an adaptive, generic, and robust feedback controller with direct application to a wide range of fed-batch production processes since only on-line biomass measurements are needed and an explicit formulation (and parametrization) of the non-monotonic kinetics is not required.

As a final critical remark, it has to be mentioned that the control of very small substrate concentrations is only possible with substrate or substrate-related on-line measurement (31). If, for example, the setpoint concentrations and kinetic parameters employed in the study of phenol degradation conducted by Léonard et al. are considered (5), the $C_{x}$-based $\mu$-observer, as developed here, will fail.

\section{Notation}

t time [h]

$\mathrm{C}_{\mathrm{S}} \quad$ (limiting) substrate concentration $[\mathrm{g} / \mathrm{L}]$

$\mathrm{C}_{\mathrm{S}}^{*} \quad$ substrate concentration setpoint $[\mathrm{g} / \mathrm{L}]$

$\mathrm{C}_{\mathrm{S}, \mathrm{a}}^{*} \quad$ substrate concentration associated with setpoint $\mathrm{C}_{\mathrm{S}}^{*}$ $[g / L]$

$C_{X}$ biomass concentration $[\mathrm{g} / \mathrm{L}]$

$\widehat{\mathrm{C}_{x}}$ biomass concentration estimate $[\mathrm{g} / \mathrm{L}]$

$\mathrm{V}$ volume of the liquid phase in the reactor [L]

u flow rate $[\mathrm{L} / \mathrm{h}]$

$\mathrm{C}_{\mathrm{s}, \mathrm{in}}$ influent substrate concentration $[\mathrm{g} / \mathrm{L}]$

$Y_{x / S}$ yield coefficient of biomass on substrate [-]

$K_{\mathrm{P}} \quad$ Haldane kinetics constant $[\mathrm{g} / \mathrm{L}]$

$\mathrm{K}_{\mathrm{I}} \quad$ Haldane kinetics constant $[\mathrm{g} / \mathrm{L}]$

$\mathrm{C}_{\mathrm{S}, u}$ substrate concentration corresponding with maximum specific growth rate (numerical value equals $\left.\sqrt{\mathrm{K}_{1} \mathrm{~K}_{\mathrm{p}}}\right)[\mathrm{g} / \mathrm{L}]$

f $\quad$ switch factor equal to +1 or $-1[-]$

$E_{C} \quad$ controller performance related cost function [-]

$E_{0,1}$ observer related cost function (convergence) $\left[(\mathrm{g} / \mathrm{L})^{2}\right]$

$\mathrm{E}_{0,2}$ observer related cost function (noise sensitivity) [(1/ h) $\left.)^{2}\right]$

$\mu \quad$ specific growth rate $[1 / h]$

$\mu^{*} \quad$ specific growth rate setpoint $[1 / \mathrm{h}]$

$\hat{\mu} \quad$ specific growth rate estimate [1/h]

$\mu_{\mathrm{m}} \quad$ Haldane kinetics constant $[1 / \mathrm{h}]$

$\sigma \quad$ specific substrate consumption rate $[1 / \mathrm{h}]$

$\alpha \quad$ a positive constant involving kinetic parameters and the substrate concentration (setpoint) $\left[\mathrm{L}^{3} / \mathrm{h} \mathrm{g}^{3}\right]$

$\tau_{\mathrm{C}_{\mathrm{S}}} \quad$ tuning parameter of $\left(\mathrm{C}_{\mathrm{S}}, \mathrm{C}_{\mathrm{X}}\right)$-based controller [1/h]

$\tau_{\mu} \quad$ tuning parameter of $\left(\mathrm{C}_{\mathrm{X}}\right)$-based controller $[\mathrm{g} / \mathrm{L}]$

$\gamma \quad$ tuning parameter of observer $\left[\mathrm{L}^{2} /\left(\mathrm{g}^{2} \mathrm{~h}^{2}\right)\right]$

$\omega \quad$ tuning parameter of observer $[1 / \mathrm{h}]$

$\lambda \quad$ user-defined eigenvalue to determine $\gamma$ and $\omega[1 / h]$

$\phi \quad$ user-defined factor to equalize order of magnitude of observer related cost functions $\left[g^{2} \mathrm{~h}^{2} / \mathrm{L}^{2}\right]$ 
$\epsilon_{\mu} \quad$ user-defined limit of specific growth rate deviation in eq $10[1 / \mathrm{h}]$

\section{Acknowledgment}

I.S. is a research assistant with the Fund for Scientific Research-Flanders (FWO). Work supported in part by project OT/99/24 of the Research Council of the Katholieke Universiteit Leuven, and the Belgian Program on Interuniversity Poles of Attraction, initiated by the Belgian State, Prime Minister's Office for Science, Technology and Culture. The authors also want to acknowledge the reviewers for their interesting and helpful suggestions. The scientific responsibility is assumed by the authors.

\section{References and Notes}

(1) Gregory, M. E.; Turner, C. Open-loop control of specific growth rate in fed-batch cultures of recombinant Escherichia coli. Biotechnol. Tech. 1993, 7, 889-894.

(2) Yoon, S. K.; Kang, W. K.; Park, T. H. Fed-batch operation of recombinant Escherichia coli containing trp promotor with controlled specific growth rate. Biotechnol. Bioeng. 1994, 43, 995-999.

(3) Paalme, T.; Tiisma, K.; Kahru, A.; Vanatalu, K.; Vilu, R. Glucose-limited fed-batch cultivation of Escherichia coli with computer-controlled fixed growth rate. Biotechnol. Bioeng. 1990, 35, 312-319.

(4) d'Anjou, M. C.; Daugulis, A. J. A rational approach to improving productivity in recombinant Pichia pastoris fermentation. Biotechnol. Bioeng. 2001, 72, 1-11.

(5) Léonard, D.; Ben Youssef, C.; Destruhaut, C.; Lindley, N. D.; Queinnec, I. Phenol degradation by Ralstonia eutropha: colorimetric determination of 2-hydroxymuconate semialde hyde accumulation to control feed strategy in fed-batch fermentati ons. Bi otechnol. Bi oeng. 1999, 65, 407-415.

(6) Kleman, G. L.; Chalmers, J . J .; Luli, G. W.; Strohl, W. R. A predictive and feedback control algorithm maintains a constant glucose concentration in fed-batch fermentations. Appl. Environ. Microbiol. 1991, 57, 910-917.

(7) Turner, C.; Gregory, M. E.; Thornhill, N. F. Closed-loop control of fed-batch cultures of recombinant Escherichia coli using on-line HPLC. Biotechnol. Bioeng. 1994, 44, 819-829.

(8) Shimizu, N.; Fukuzono, S.; Fujimori, K.; Nishimura, N.; Odawara, Y. F ed-batch cultures of recombinant Escherichia coli with inhibitory substance concentration monitoring. J . Ferment. Technol. 1988, 66, 187-191.

(9) Pons, M.-N.; Rajab, A.; Engasser, J .-M. I nfluence of acetate on growth kinetics and production of Saccharomyces cerevisiaeon glucose and ethanol. Appl. Microbi ol. Biotechnol. 1986, 24, 193-198.

(10) Aiba, S.; Nagai, S.; Nishizawa, Y. Fed batch culture of Saccharomyces cerevisiae: a perspective of computer control to enhance the productivity in baker's yeast cultivation. Biotechnol. Bioeng. 1976, 18, 1001-1016.

(11) Wang, H. Y.; Cooney, C. L.; Wang, D. I. C. Computer-aided baker's yeast fermentations. Biotechnol. Bioeng. 1977, 19, 69-86.

(12) Cooney, C. L.; Wang, H. Y.; Wang, D. I . C. Computer-aided material balancing for prediction of fermentation parameters. Biotechnol. Bioeng. 1977, 19, 55-67.

(13) Williams, D.; Y ousefpour, P.; Wellington, E. M. H. On-line adaptive control of a fed-batch fermentation of Saccharomyces cerevisiae. Biotechnol. Bioeng. 1986, 28, 631-645.
(14) Beluhan, D.; Gosak, D.; Pavlović, N.; Vampola, M. Biomass estimation and optimal control of the baker's yeast fermentation process. Comput. Chem. Eng. 1995, 19, S387-S392.

(15) Dairaku, K.; Yamasaki, Y.; Kuki, K.; Shioya, S.; Takamatsu, T. Maximum production in a baker's yeast fed-batch culture by a tubing method. Biotechnol. Bioeng. 1981, 23, 2069-2081.

(16) Nanba, A.; Hirota, F.; Nagai, S. Microcomputer coupled baker's yeast production. J . Ferment. Technol . 1981, 59, 383389.

(17) Axelsson, J . P.; Mandenius, C. F .; Holst, O.; Hagander, P.; Mattiasson, B. Experience in using an ethanol sensor to control molasses feed-rates in baker's yeast production. Bioprocess Eng. 1988, 3, 1-9.

(18) Hagander, P.; Axelsson, J . P.; Holst, O. Substrate control of biotechnical fedbatch processes robustness and the role of adaptivity. In Preprints of the 11th IFAC World Congress, 1990; Vol. 11, pp 280-285.

(19) Valentinotti, S.; Holmberg, U.; Cannizzaro, C.; Bonvin, D. Modeling for control of fed-batch fermentors. In Preprints of ADCHEM 2000, IFAC Internati onal Symposium on Advanced Control of Chemical Processes; Biegler, L., Brambilla, A., Scali, C., Marchetti, G., Eds.; Pisa, 2000; Vol. 1, pp 491-496.

(20) Chen, L.; Bastin, G.; Van Breusegem, V. A case study of adaptive nonlinear regulation of fed-batch biological reactors. Automatica 1995, 31, 55-65.

(21) Chen, L.-H.; Chang, H.-C. Global stabilization of a biological reactor by linear feedback control. Chem. Eng. Commun. 1984, 27, 231-254.

(22) Kirk, D. E. Optimal Control Theory: an Introduction; Prentice Hall: Englewood Cliffs, NJ , 1970.

(23) Van Impe, J . F.; Bastin G. Optimal adaptive control of fedbatch fermentation processes. Control Eng. Practice 1995, 3, 939-954.

(24) Åkesson, M.; Karlsson, E. N.; Hagander, P.; Axelsson, J. P.; Tocaj, A. On-line detection of acetate formation in Escherichia coli cultures using dissolved oxygen responses to feed transients. Biotechnol. Bioeng. 1999, 64, 590-598.

(25) Van Impe, J . F. Optimal control of fed-batch fermentation processes. In Advanced Instrumentation, Data I nterpretation and Control of Biotechnical Processes; Van Impe, J. F., Vanrolleghem, P., Iserentant, D., Eds.; Kluwer Academic Publishers: Dordrecht, 1998; pp 319-346.

(26) Claes, J . E.; Van Impe, J . F. On-line estimation of the specific growth rate based on viable biomass measurements: experimental validation. Bioprocess Eng. 1999, 21, 389-395.

(27) November, E. J .; Van Impe J. F. Evaluation of on-line viable biomass measurements during fermentations of Candida utilis. Bioprocess Eng. 2000, 23, 473-477.

(28) Yamané, T.; Kishimoto, M.; Y oshida, F. Semi-batch culture of methanol-assimilating bacteria with exponentially increased methanol feed. J . Ferment. Technol. 1976, 54, 229240.

(29) Bastin, G.; Dochain, D. On-Line Estimation and Adaptive Control of Bioreactors; Elsevier Science: Amsterdam, The Netherlands, 1990.

(30) Davey, C. L. TheBiomass Monitor SourceBook. A Detailed User Guide; Aber Instruments Ltd.: Aberystwyth, Wales, 1993.

(31) Ghoul, M.; Ronat, E.; Engasser, J .-M. An automatic and sterilizable sampler for laboratory fermentors: application to the on-line control of glucose concentration. Biotechnol. Bioeng. 1986, 28, 119-121.

Accepted for publication J uly 8, 2002.

BP010191P 